\title{
Pseudohypertrophy of muscles of thenar eminence in X-linked muscular dystrophy (Becker type)
}

\author{
H. G. BoDDIE \\ M.B., M.R.C.P.
}

\author{
J. WADE \\ M.B., M.R.C.P.
}

Department of Neurology, North Staffordshire Royal Infirmary, Stoke-on-Trent

\section{Summary}

A case of benign $X$-linked muscular dystrophy is described in which the distribution of pseudohypertrophy is unusual.

\section{Introduction}

$\mathrm{X}$-linked muscular dystrophy (MD) occurs in 2 forms, mild and severe. The severe type, first described by Duchenne in 1868 , is characterized by presentation before the age of 6 years, rapid progression of muscle weakness, inability to walk by the age of 12 years and death before the age of 20 years. It was Becker and Kiener (1955) who first delineated a 'benign' form, in which the condition presents later and pursues a slower course. This is a distinct entity and not simply a part of a spectrum of severity. Whether or not the mild type should be further subdivided remains debatable (Shaw and Dreiffuss, 1969). In both forms, muscular pseudohypertrophy, especially of the calf muscles, is common. A case is now reported of Becker (mild type) MD in which pseudohypertrophy of the muscles of the thenar eminence was prominent.

\section{Case report}

A 28-year-old Malaysian gave an 8-year history of inability to run, difficulty in climbing stairs and getting out of low chairs. He had noticed large calves for as long as he could remember. $\mathrm{He}$ is one of 10 sibs and of his 3 brothers 2 have similar symptoms. The family live in Malaysia.

Examination showed marked pseudohypertrophy of the calf muscles, infraspinati and muscles of the thenar eminences (Fig. 1). Power in the arms was normal apart from bilateral weakness of abductor pollicis brevis and opponens pollicis. In the legs there was weakness of hip flexors and extensors. The thighs were wasted and knee extension was very weak. His gait was waddling with an exaggerated lumbar lordosis. The deep tendon reflexes were normal apart from absent knee jerks. No other neurological or general abnormality was found.

Abnormal investigations included a CPK of
$1045 \mathrm{u} . / \mathrm{l}$, serum aldolase of $11.6 \mathrm{u} . / \mathrm{l}$ and SGOT of $61 \mathrm{u} . / \mathrm{l}$. ECG showed deep Q waves in the inferior leads and $\mathrm{R}$ wave abnormalities in the chest leads

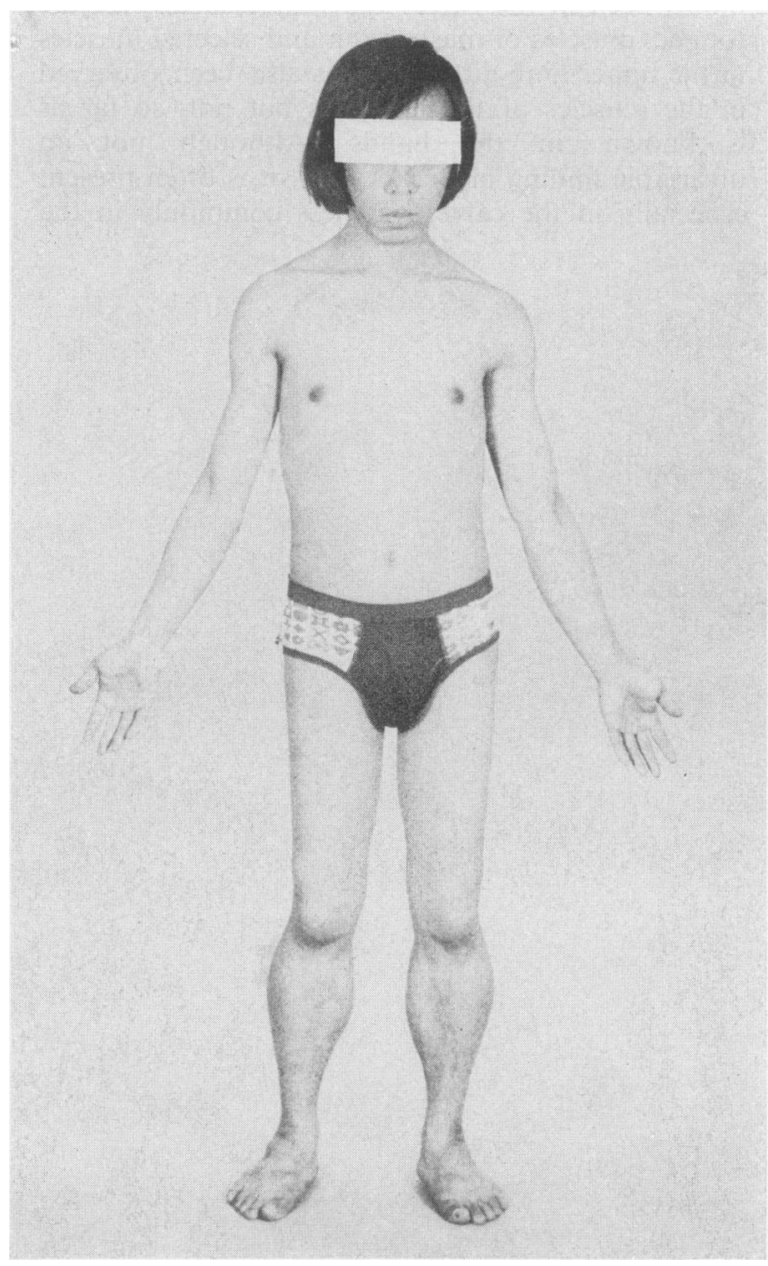

FIG. 1. Illustration showing marked hypertrophy of calf muscles and thenar eminences. 
suggestive of biventricular hypertrophy. On electromyographic examination low amplitude, short duration polyphasic potentials were noted in all muscles sampled including the left abductor pollicis brevis. Conduction velocities were normal. A left gastrocnemius muscle biopsy revealed marked variation in fibre size with evidence of necrosis and focal lymphocytic infiltration. Oxidative histochemical techniques showed that types I and IIA were most affected.

\section{Discussion}

The history, examination and histological findings in this patient support a diagnosis of Becker MD with the unique addition of pseudohypertrophy of the muscles of the thenar eminences. In Duchenne MD, muscular pseudohypertrophy is most commonly seen in the calves but may also involve the tongue, muscles of mastication and selected muscles in the upper limb girdles. It has also been observed in the muscles of the forearms but not, so far as is known, in the hands. Although not an invariable finding in Becker MD, it is often present especially in the calves and less commonly in the tongue, infraspinati and deltoids (Becker, 1962; 3 Emery and Skinner, 1976; Mabry et al., 1965; ;® Ringel, Carroll and Schold, 1977; Shaw and.. Dreiffuss, 1969).

\section{References}

BECKER, P.E. \& KIENER, F. (1955) Eine neue X chromosomale Muskel Dystrophie. Archives Psychiatrie Nevenka, 193, $\mathbb{\mathbb { Q }}$ 427.

BECKER, P.E. (1962) Two new families of benign sex-linked ڤँ muscular dystrophy. Review of Canadian Biology, 21, 551.-

DUCHENNE, G.-B. (1868) Recherches sur la paralysie muscu-? laire pseudohypertrophique ou paralysie myosclérosique. $\overrightarrow{\mid}$ Archives générales et Médecine, Série B., 11, 5, 179, 305, 421, 552.

EMERY, A.E.H. \& SKInNeR, R. (1976) Clinical studies ino benign (Becker type) X-linked muscular dystrophy 3 . Clinical Genetics, 10, 189.

Mabry, C.C., Roeckel, I., Munich, R. \& Robertson, D.の (1965) X-linked pseudo-hypertrophic muscular dystrophy with late onset and slow progression. New EnglandN Journal of Medicine, 273, 1052.

Ringel, S.P., Carroll, J.E. \& Schold, S.C. (1977) The $\vec{G}$ spectrum of mild X-linked recessive muscular dystrophy.음 Archives of Neurology, 34, 408.

Shaw, R.F. \& Dreiffuss, F.E. (1969) Mild and severe forms of X-linked muscular dystrophy. Archives of Neurology, 20, 451. 